\title{
A assistência integral à saúde dos adolescentes privados de liberdade no Brasil:
}

\section{avanços e limites}

\author{
Health care for adolescentes deprived of liberty in Brazil: advances and limits \\ Atención integral de salud a adolescentes privados de libertad en Brasil: avances y límites
}

Recebido: 30/08/2021 | Revisado: 04/09/2021 | Aceito: 07/09/2021 | Publicado: 08/09/2021

Denise Rissato

ORCID: https://orcid.org/0000-0001-7027-3408 Universidade Estadual do Oeste do Paraná, Brasil E-mail: denise.rissato@hotmail.com

Marcos Augusto Moraes Arcoverde

ORCID: https://orcid.org/0000-0001-5104-559X Universidade Estadual do Oeste do Paraná, Brasil

E-mail: marcos.arcoverde2013@gmail.com

Murilo Schurt Alves

ORCID: https://orcid.org/0000-0002-2436-4111 Universidade Estadual do Oeste do Paraná, Brasil

E-mail: schurtt@gmail.com

\begin{abstract}
Resumo
O objetivo deste trabalho foi refletir sobre as condições e os desafios enfrentados para a concretização do direito à saúde dos adolescentes em privação de liberdade no Brasil, a partir da criação da Política Nacional de Atenção Integral à Saúde dos Adolescentes em conflito com a Lei, criada em 2004 e reformulada e ampliada em 2014. Para tanto, realizou-se uma pesquisa bibliográfica e documental de cunho exploratório sobre o direito e o acesso à atenção integral à saúde dos adolescentes em conflito com a lei em privação de liberdade. Os documentos e artigos evocados no texto, demonstram um histórico de negação ao direito à saúde para os adolescentes institucionalizados. Concluiu-se que passadas quase duas décadas desde a criação da referida política, as dificuldades para garantir o direito à saúde dos adolescentes em conflito com a lei ainda persistem em, praticamente, todo o território nacional, seja pelos próprios desafios, subjetividades e complexidades que envolvem o trabalho socioeducativo, seja pelos interesses e prioridades políticas. Por fim, cabe ressaltar que a legislação, por si só, não garante direitos, é imperativo o comprometimento político e ético da sociedade para consolidar a socioeducação enquanto política pública educativa, inclusiva e restaurativa.
\end{abstract}

Palavras-chave: Direito à saúde; Políticas públicas de saúde; Adolescente institucionalizado; Saúde integral do Adolescente.

\begin{abstract}
The objective of this paper is to reflect on the conditions and challenges faced by adolescents in freedom deprivation in Brazil regarding the realization of health rights, from the creation of the National Policy for complete attention in Health of adolescents in conflict with the Law, created in 2004 and reworked and amplified in 2014. In order to achieve that, a bibliographical and documental research was exploratory conducted, regarding the right and access to complete attention in health of adolescents in freedom deprivation. The documents and articles evoked in the text demonstrate a history of denial of the right to health to institutionalized adolescents. It was concluded that after almost two decades since the creation of the referred policy, the difficulties to assure the right to health of adolescents in conflict with the Law still persist in virtually all national territory, be it due to challenges, subjectivities and complexities that evolve the socioeducational work, be it for the interests and political priorities. Finally, it is worth to note that the Law itself does not assure rights, it is imperative the ethical and political committment of society to consolidate socioeducation as an educational, inclusive and restorative public policy.
\end{abstract}

Keywords: Right to health; Health policy; Institutionalized adolescentes; Adolescent health.

\section{Resumen}

El objetivo de este estudio fue reflexionar sobre las condiciones y desafíos enfrentados en la realización del derecho a la salud de los adolescentes privados de libertad en Brasil, a partir de la creación de la Política Nacional de Atención Integral a la Salud del Adolescente en conflicto con la Ley, creada en 2004, reformulado y ampliado en 2014. Para ello, se realizó una investigación bibliográfica y documental exploratoria sobre el derecho y acceso a la atención integral de salud de los adolescentes en conflicto con la ley en privación de libertad. Los documentos y artículos evocados en el texto evidencian una historia de negación del derecho a la salud de los adolescentes 
institucionalizados. Se concluyó que a casi dos décadas de la creación de la referida política, las dificultades para garantizar el derecho a la salud de los adolescentes en conflicto con la ley aún persisten en prácticamente todo el territorio nacional, debido a los desafíos, subjetividades y complejidades que implican el trabajo socioeducativo, ya sea por intereses y prioridades políticas. Finalmente, cabe destacar que la legislación por sí sola no garantiza derechos. Es imperativo el compromiso político y ético de la sociedad para consolidar la socioeducación como una política pública educativa, inclusiva y reparadora.

Palabras clave: Derecho a la salud; Políticas públicas de salud; Adolescente institucionalizado; Salud Integral del Adolescente.

\section{Introdução}

A promulgação da Constituição da República Federativa do Brasil de 1988, que criou um amplo e complexo sistema público de proteção social, representou um primeiro passo no longo e árduo processo de expansão e consolidação de direitos fundamentais individuais e coletivos no Brasil. No que diz respeito, mais especificamente, aos direitos da população infantojuvenil, que se constitui em tema central para este trabalho, a referida Carta Magna prevê, em seu artigo 227, o dever e a responsabilidade compartilhada da família, da sociedade e do Estado de assegurar-lhes "o direito à vida, à saúde, à alimentação, à educação, ao lazer, à profissionalização, à cultura, à dignidade, ao respeito, à liberdade e à convivência familiar e comunitária", bem como, de protegê-la de todo e qualquer tipo de violência, exploração e discriminação (Brasil, 1988).

Essa previsão constitucional foi regulamentada pela Lei no 8.069, de 13 de julho de 1990, também conhecida como o Estatuto da Criança e do Adolescente (ECA), que reconheceu e institucionalizou o entendimento de que todas as crianças e adolescentes são detentores de todos os direitos concedidos aos adultos, desde que sejam adequadamente aplicáveis à sua idade, além de direitos específicos que decorrem de sua condição peculiar de desenvolvimento (Brasil, 1990).

Mais especificamente, no tocante ao direito à saúde de crianças e adolescentes, observa-se que, independentemente dos avanços já ocorridos desde a criação do Sistema Único de Saúde (SUS) e da Programa/Estratégia Saúde da Família (ESF), regulamentados, respectivamente, pela Lei $\mathrm{n}^{\circ} 8.080$ de 19 de setembro de 1990 e pela Portaria GM/MS no 1.886 de 18 de dezembro de 1997, assegurar tal direito ainda é um grande desafio a ser enfrentado pela sociedade brasileira (Brasil, 1990; 1997).

Para Perminio et al. (2018), as principais barreiras que dificultam o maior acesso de crianças e adolescentes aos serviços de saúde são o desconhecimento sobre os serviços, a negação do atendimento quando os menores de idade estão desacompanhados dos pais e a dificuldades da atenção básica à saúde em dar respostas às necessidades dessa população compatíveis com sua fase de desenvolvimento.

Contudo, acredita-se que essa situação tende a se agravar no caso dos adolescentes em conflito com a lei que cumprem medida socioeducativa de internação. Primeiramente, porque tanto o isolamento social e o processo de adaptação às rotinas e normas institucionais, quanto as condições objetivas de sobrevivência dentro das unidades de internamento são capazes de gerar desconforto emocional e produzir o adoecimento físico e psíquico. Em segundo lugar, porque o acesso ao atendimento integral à saúde, nesses casos, está condicionado não apenas à disponibilidades de recursos e das condições materiais asseguradas pelo Estado, mas também à subjetividade dos profissionais que trabalham nas instituições de internação e na rede de proteção que, como sujeitos sociais, muitas vezes, acabam reproduzindo em suas práxis, mesmo que involuntariamente, seus valores, seus preconceitos e sua compreensão da realidade social (Alves, Rissato \& Arcoverde, 2020). Com isso, muitas vezes, o adolescente em conflito com a lei passa a ser punido não apenas com a privação de liberdade, mas também com a negação de outros direitos fundamentais, como o direito à saúde.

Em decorrência disso, quatorze anos depois da promulgação do ECA, considerando as evidências de violações do direitos à saúde dos adolescentes em conflito com a lei, bem como, os inúmeros obstáculos tanto de cunho material quanto de caráter subjetivo e discricionário, que se colocavam à efetivação do direito à saúde deste público, o Ministério da Saúde, em 
parceria com a Secretaria Especial de Direitos Humanos e a Secretaria Especial de Políticas para as Mulheres, publicou a Portaria $n^{\circ} 1.426$ de 14 de julho de 2004, instituindo as diretrizes para a implantação e a operacionalização da Política Nacional de Atenção Integral à Saúde de Adolescentes em Conflito com a Lei em regime de internação e internação provisória PNAISARI (Brasil, 2004).

Uma década depois, assumindo o princípio da incompletude institucional e com o objetivo de ampliar a garantia do acesso e o alcance populacional da Pnaisari, o Ministério da Saúde publicou a Portaria GM/MS n 1.082 , de 23 de maio de 2014, redefinindo suas diretrizes, assegurando o acesso à atenção integral à saúde a todos os adolescentes em cumprimento de medida socioeducativa em regime aberto (Medida de Prestação de Serviço à Comunidade e Medida de Liberdade Assistida) e em regime fechado (Semiliberdade, Internação Provisória e Internação) e estabelecendo novos critérios e fluxos para adesão e realização da atenção integral à saúde dos adolescentes em restrição e/ou privação de liberdade (Brasil, 2014).

Diante disso, neste trabalho buscou-se refletir sobre as condições e os desafios enfrentados para a concretização do direito à saúde dos adolescentes em privação de liberdade no Brasil, a partir da criação da Pnaisari em 2004. Para tanto, realizou-se uma pesquisa bibliográfica e documental de cunho exploratório sobre o direito e o acesso à atenção integral à saúde dos adolescentes em conflito com a lei que cumprem medidas socioeducativas em privação de liberdade no Brasil (Lima, 2011; Köche, 2011).

\section{Adolescentes em Conflito com a Lei em Cumprimento de Medida Socioeducativa de Internação e o seu Direito à Saúde Integral}

O ECA instituiu mecanismos específicos de defesa, tutela e proteção integral e prioritária de todas as crianças e adolescentes, em decorrência de sua condição peculiar de desenvolvimento. Dentre os principais avanços trazidos pelo referido estatuto, destacam-se as diretrizes orientadoras da ação estatal em relação aos adolescentes em conflito com a lei, que incluem seis diferentes modalidades de medidas socioeducativas que podem ser aplicadas pelas autoridades competentes aos adolescentes que cometerem atos infracionais, a saber: advertência, obrigação de reparar o dano, prestação de serviços à comunidade, liberdade assistida, semiliberdade e internação (privação de liberdade em unidade socioeducativa) (Brasil, 1990).

Com isso, percebe-se que os formuladores dessa política visavam a superação das práticas meramente punitivas, segregadoras e estigmatizadoras, até então adotadas, por outras de cunho pedagógico voltadas à educação, à formação e ao desenvolvimento de novas sociabilidades, bem como, assegurar e promover o acesso, desses adolescentes, aos direitos individuais e sociais.

Considerando que neste trabalho será dada ênfase ao direito à atenção integral à saúde dos adolescentes que cumprem medidas socioeducativas em privação de liberdade no Brasil, daqui por diante as discussões serão centradas, mais especificamente, na medida socioeducativa de internação provisória e internação.

A medida socioeducativa de internação, prevista nos artigos 121 a 123 do ECA, implica no cerceamento da liberdade integral do adolescente, sendo permitidas atividades externas desde que autorizadas pela equipe dirigente da instituição, salvo expressa determinação judicial em contrário. Tendo em vista o caráter eminentemente punitivo dessa medida socioeducativa, bem como, os seus possíveis efeitos deletérios sobre a saúde desses adolescentes, a mesma só pode ser aplicada em ultima ratio, nos casos em que os atos infracionais cometidos representem grave ameaça ou violência à pessoa, quando constatada a reincidência e/ou reiteração no cometimento de infrações graves ou, ainda, por descumprimento de medida socioeducativa anteriormente imposta (Brasil, 1990). No entanto, para Calderoni (2010), mesmo nesses casos, a aplicação da medida socioeducativa de internação deve levar em conta o princípio da excepcionalidade que, deve ser verificado no momento da imposição da medida pelo juiz, avaliando o caso concreto e considerando, sempre, a internação como última opção por ser a mais extrema e severa dentre as medidas socioeducativas previstas na legislação vigente. 
Não obstante, o regime de internação não comporta prazo determinado, embora tenha uma duração máxima de três anos com reavaliações periódicas a cada seis meses. Este preceito está diretamente relacionado ao princípio da brevidade e o posicionamento do Sistema Nacional de Atendimento Socioeducativo - SINASE, que considera imprescindível a convivência do adolescente no meio familiar e comunitário para que a experiência socioeducativa não restrinja, de modo demasiado e prolongado, o seu direito à cidadania, uma vez que o mesmo somente pode efetivar-se quando o indivíduo participa plenamente da vida em sociedade (Brasil, 2006).

Além da internação em sentido estrito, também cabe a possibilidade do adolescente em conflito com a lei cumprir o regime de internação provisória. Segundo Bandeira (2006), a internação provisória consiste em uma medida constritiva de caráter cautelar, independentemente do ato ter sido praticado com ou sem violência grave ou ameaça, objetivando garantir a segurança e integridade física do adolescente, bem como, do meio social e da ordem pública.

Conforme o artigo 183 do ECA, o prazo máximo e improrrogável de cumprimento da internação provisória não poderá ultrapassar 45 dias (Brasil, 1990). De acordo com Bandeira (2006), o processo decisório sobre a pertinência da aplicação dessa medida também deverá levar em consideração se há indícios suficientes de autoria do ato infracional, se a situação revela necessidade imperiosa de privação de liberdade, bem como, se o histórico comportamental do adolescente indica reincidência na prática de atos infracionais.

No que diz respeito, mais especificamente ao direito à atenção integral à saúde, a Lei no 12.594 de 18 de janeiro de 2012 (Brasil, 2012), estabelece que o atendimento de adolescentes em regime de internação e internação provisória deve assegurar o cumprimento da PNAISARI que, por sua veze, define como prioridades o desenvolvimento de estratégias de promoção integral da saúde que assegurem um ambiente institucional saudável e que promovam o autocuidado, as relações interpessoais e o fortalecimento da rede de apoio institucional (Brasil, 2004).

Além disso, a PNAISARI determina, no seu artigo $1^{\circ}, \S 2^{\circ}$, o dever do Estado de assegurar por meio de uma série de medidas educativas, preventivas e de cuidados específicos à saúde dos adolescentes internos, com ênfase à saúde mental, aos agravos psicossociais, ao uso de álcool e drogas, à saúde sexual e reprodutiva, mediante uma programação pactuada, integrada e negociada pelas Comissões Intergestores Bipartites (Brasil, 2004), compostas por membros da Secretaria de Estado da Saúde e por gestores municipais indicados pelo Conselho de Secretarias Municipais de Saúde de cada estado, reiterando a concepção expressa no ECA que prevê um conjunto de ações articuladas e compartilhadas entre entidades governamentais e nãogovernamentais para a organização das políticas voltadas à infância e à adolescência (Brasil, 1990).

Corroborando com esse entendimento, o SINASE estabelece que,

[...] a política de aplicação das medidas socioeducativas não pode estar isolada das demais políticas públicas. Os programas de execução de das Secretar atendimento socioeducativo deverão ser articulados com os demais serviços e programas que visem atender os direitos dos adolescentes (saúde, defesa jurídica, trabalho, profissionalização, escolarização, etc). Dessa forma, as políticas sociais básicas, as políticas de caráter universal, os serviços de assistência social e de proteção devem estar articulados aos programas de execução das medidas socioeducativas, visando assegurar aos adolescentes a proteção integral. A operacionalização da formação da rede integrada de atendimento é tarefa essencial para a efetivação das garantias dos direitos dos adolescentes em cumprimento de medidas socioeducativas, contribuindo efetivamente no processo de inclusão social do público atendido (Brasil, 2006, p. 29).

De acordo com a Portaria GM/MS no $1.082 / 2014$, a PNAISARI passa a contemplar também os adolescentes em conflito com a lei que cumprem medidas socioeducativas em regime aberto. Além disso, também instituiu importantes alterações à primeira versão da PNAISARI, publicada em 2004, tais como: a criação de grupos de trabalho intersetorial para a elaboração de planos operativos, de ação anual e daqueles de monitoramento da efetiva implementação da política; ampliação de recursos repassados diretamente do Fundo Nacional de Saúde para o ente federado responsável pela realização da referida 
política; inclusão de profissionais de saúde mental na equipe de referência da atenção básica, por se tratar de uma das principais demandas em saúde dessa população; flexibilização das exigências arquitetônicas para construção e/ou ampliação dos espaços de saúde dentro das unidades socioeducativas; possibilidade de habilitação direta do município e, por consequência, a descentralização da gestão; plano de ação anual vinculado ao recebimento do incentivo financeiro do ano vigente; visitas in loco para acompanhamento e fiscalização; suspensão do financiamento quando houver equipes incompletas, cadastros desatualizados ou não envio do plano de ação anual (Brasil, 2004, 2014).

A despeito de que, a partir de 2014, a PNAISARI expandiu o seu escopo, ampliando o direito à atenção integral de saúde para os adolescentes em cumprimento de qualquer uma das modalidades de medida socioeducativa (regime aberto e fechado), neste texto, busca-se identificar as condições e os desafios que se impõe à concretização do direito à saúde dos adolescentes em privação de liberdade no Brasil. Isto posto, a seguir serão apresentadas algumas reflexões sobre a privação de liberdade e a saúde.

\section{Alguns Apontamentos Sobre Privação de Liberdade e Saúde}

O sociólogo canadense Erving Goffman, ao estudar a realidade enfrentada por indivíduos internados em instituições mais tradicionais de confinamento, denominou os estabelecimentos com privação de liberdade como "instituições totais". Nas palavras do autor, "uma instituição total pode ser definida como um local de residência e trabalho onde um grande número de indivíduos em situação semelhante, separados da sociedade mais ampla por considerável período de tempo, levam uma vida fechada e formalmente administrada" (Goffman, 2003, p. 11). Essas instituições caracterizam-se por barreiras institucionais e físicas que impedem o acesso ao mundo externo, levando a um processo de naturalização das relações sociais, mesmo em um espaço restrito, em confinamento. Embora existam várias modalidades de instituições totais, de linhas gerais, elas apresentam as seguintes características comuns:

Em primeiro lugar, todos os aspectos da vida são realizados no mesmo local e sob uma única autoridade. Em segundo lugar, cada fase da atividade diária do participante é realizada na companhia imediata de um grupo relativamente grande de outras pessoas, todas elas tratadas da mesma forma e obrigadas a fazer as mesmas coisas em conjunto. Em terceiro lugar, todas as atividades diárias são rigorosamente estabelecidas em horários, pois uma atividade leva, em tempo predeterminado, à seguinte, e toda a sequência de atividades é imposta de cima, por um sistema de regras formais explícitas e um grupo de funcionários. Finalmente, as várias atividades obrigatórias são reunidas num plano racional único, supostamente planejado para atender aos objetivos oficiais da instituição (Goffman, 2003, p. 16).

Percebe-se que, apesar de Goffman (2003) ter estudado especificamente as prisões, manicômios e conventos, o conceito de instituição total também se aplica às unidades de medida socioeducativa de internação, uma vez que elas também apresentam tais características. Desse modo, acredita-se que suas ideias são de fundamental importância para compreender os alcances e os riscos da institucionalização à saúde integral das pessoas privadas de liberdade, sobretudo, no caso dos adolescentes em conflito com a lei, em decorrência de suas peculiares condições de desenvolvimento. $\mathrm{O}$ autor supracitado ainda enfatiza os efeitos do confinamento sobre o comportamento e o bem-estar físico e psicológico dos indivíduos a ele submetidos.

O novato chega ao estabelecimento com uma concepção de si mesmo que se tornou possível por algumas disposições sociais estáveis no seu mundo doméstico. Ao entrar, é imediatamente despido do apoio dado por tais disposições. [...] começa uma série de rebaixamentos, degradações, humilhações e profanações do eu. O seu eu é sistematicamente, embora muitas vezes não intencionalmente, mortificado. Começa a passar por algumas mudanças radicais em sua carreira moral, uma carreira composta pelas progressivas mudanças que ocorrem nas crenças que têm a seu respeito e a respeito dos outros que são significativos para ele (Goffman, 2003, p. 24).

Segundo Goffman (2003), o indivíduo ao ser confinado e afastado de suas relações familiares e sociais, é também privado das solidariedades próximas que, em alguma medida, lhe proporcionavam sentimentos de segurança, acolhimento e 
pertencimento. Isso, por si só, tem efeitos deletérios sobre a personalidade, o comportamento e o bem-estar físico e psicológico, tendo em vista o isolamento social prolongado em relação ao mundo externo, pode levar a um processo de 'mortificação do eu' e de "desculturamento" do indivíduo. Em outras palavras, a privação de liberdade prolongada tende a desconectar o indivíduo da vida real e cotidiana, dos seus desafios e dificuldades concretas, processo este que acaba por reduzir suas chances de reinserção no mundo externo, em períodos posteriores.

Sob essa perspectiva, entende-se que o mesmo pode acontecer com os adolescentes em conflito com a lei privados de liberdade e de sua rede convivência próxima. Do mesmo modo, acredita-se também que essa situação pode a ser agravada pelas experiências pessoais anteriores e por questões inerentes ao desenvolvimento pessoal e à idade, quanto pelas condições ressocializadoras e pedagógicas nem sempre adequadas, visto que ao serem submetidos à internação, na maioria das vezes, também são obrigados a viver em condições com as quais não se identificam, quase sempre definidas por regras institucionais, normalmente criadas por uma equipe de dirigentes que precisam controlar um grande número de pessoas em um pequeno espaço e com poucos recursos (Alves, Rissato \& Arcoverde, 2020).

Ainda, nesse sentido, percebe-se que, os adolescentes em conflito com a lei, a despeito de que sejam assistidos como indivíduos em peculiar condição de desenvolvimento, quando são submetidos a uma experiência de institucionalização prolongada, poderão ter maiores dificuldades tanto para adequar-se às rotinas e regras institucionais quanto para o retorno à vida comunitária.

Por fim, Tanger (2011), corrobora com esse pensamento destacando que essa desconexão sociocultural abrupta, decorrente de processo de privação de liberdade, pode contribuir para aprofundar, no adolescente, um sentimento de frustração e de incapacidade de lidar com o mundo externo, levando-o, muitas vezes, a reincidir na prática infracional e, até mesmo, ao desejo de permanecer na instituição, onde se sente protegido e adequado ao sistema burocrático imposto.

\section{O Direito à Atenção Integral à Saúde dos Adolescentes que Cumprem Medida Socioeducativa de Internação: Evidências da Experiência Brasileira}

A despeito das inegáveis conquistas positivadas pela PNAISARI, no âmbito do direito à atenção integral à saúde dos adolescentes em conflito com a lei, inúmeros estudos sobre as condições de realização dessa política, sobretudo no caso dos adolescentes que cumprem medida socioeducativa de internamento, revelam que realidade concreta vivenciada por esses adolescentes está muito aquém daquela prevista e assegurada em lei. Em outras palavras, há um expressivo distanciamento entre o ideal jurídico do direito positivado e os direitos propriamente efetivados (Boas, Cunha \& Carvalho, 2010; Constantino, 2019).

Diante disso, a seguir serão apresentados os resultados de algumas pesquisas empíricas sobre as reais condições de realização da PNAISARI, evidenciando os fatores que impedem o alcance social dessa política e comprometem a efetivação do direito à saúde dos adolescentes em conflito com a lei internados.

Os resultados de uma inspeção realizada, pelo Conselho Federal de Psicologia - CFP e pela Ordem dos Advogados do Brasil - OAB (2006), em unidades de internação de adolescentes em conflito com a lei, localizadas em 22 Estados e no Distrito Federal, revelaram situações de violações do direito à saúde dos adolescentes institucionalizados. Cabe destacar que, embora se trate de uma pesquisa bastante antiga, realizada apenas dois anos depois de ter sido instituída a PNAISARI, diversos estudos realizados posteriormente seguiram constatando que as precárias condições objetivas e subjetivas de realização dessa política ainda persistem, impondo sérios limites à concretização do direito à saúde integral dessa população (CFP, 2010; Arêas, Constantino \& Assis, 2017; Constantino, 2019; Oliveira, 2020).

Assim, optou-se por apresentar, no Quadro 1, uma síntese dos principais problemas identificados nas unidades inspecionadas, das cinco macrorregiões brasileiras. Para isso, os problemas diagnosticados que, em alguma medida, 
representam violações ao direito à saúde dos adolescentes foram agrupados por categorias, a saber: instalações físicas; problemas de higiene; condições de saúde do adolescente; tratamento e ações preventivas; formas de violência e condições de atendimento (CFP/OAB, 2006).

Nas regiões Norte, Nordeste, Centro-Oeste e Sudeste foram encontradas instituições de internação com instalações físicas precárias e insalubres que vão desde a falta de ventilação, instalações elétricas e hidráulicas inadequadas, banheiros quebrados, sem chuveiro e sem portas, até camas quebradas e colchões sujos e estragados. Além das instalações físicas impróprias, as celas são superlotadas onde, normalmente, são alojados entre 5 e 7 adolescentes em espaços com capacidade máxima para 04 pessoas (Quadro 1).

Quadro 1 - Diagnóstico situacional das condições de desenvolvimento da socioeducação nas Macrorregiões, Brasil, 2006.

\begin{tabular}{|c|c|c|c|c|c|}
\hline Condições constatadas nos centros de internação & $\mathbf{N}$ & NE & $\mathrm{CO}$ & SE & $\mathbf{S}$ \\
\hline $\begin{array}{l}\text { a) Instalações físicas } \\
\text { - Instalações físicas precárias, insalubres, superlotadas } \\
\text { - } \quad \text { camas quebradas; } \\
\text { - } \quad \text { falta de ventilação, umidade, mau odor, celas alagadas, } \\
\text { - } \quad \text { instalação elétrica inadequada, falta de energia elétrica; banheiros quebrados e } \\
\text { sem privacidade, banhos frios; } \\
\text { - } \quad \text { superlotação; }\end{array}$ & $\mathrm{X}$ & $\mathrm{X}$ & $\mathrm{X}$ & $\mathrm{X}$ & - \\
\hline $\begin{array}{l}\text { b) Problemas de higiene } \\
\text { - Quantidade insuficiente de roupas e de peças íntimas, o que levava o adolescente } \\
\text { a permanecer vários dias com as mesmas roupas; } \\
\text { - } \quad \text { Limpeza precária das instalações, às vezes realizada pelos próprios adolescentes } \\
\text { apenas quando havia material de limpeza; } \\
\text { - } \quad \text { Fornecimento de alimentos em mau estado de preparo e conservação. }\end{array}$ & $\mathrm{X}$ & $X$ & $X$ & $X$ & X \\
\hline $\begin{array}{l}\text { c) Condições de saúde do adolescente } \\
\text { - Problemas de saúde recorrentes (dermatoses - escabiose, pano branco, } \\
\text { furunculose, doenças respiratórias, ausência de controle de doenças como } \\
\text { tuberculose, DST/HIV/Aids, catapora, casos de transtornos psíquicos em } \\
\text { decorrência de deficiências e drogadição) e } \\
\text { - Sem acesso a tratamento, a profissionais ou a serviços de atendimento. } \\
\text { - Problemas odontológicos. }\end{array}$ & $\mathrm{X}$ & $\mathrm{X}$ & $\mathrm{X}$ & $\mathrm{X}$ & $\mathrm{X}$ \\
\hline $\begin{array}{l}\text { d) Tratamento e ações preventivas } \\
\text { - } \quad \text { Queixa de falta de medicamentos; } \\
\text { - } \quad \text { Não realiza ações de prevenção para novos casos de doenças infecciosas. } \\
\text { - } \quad \text { Sintomas como dor de cabeça, febre e desconforto estomacal ficam sem } \\
\text { tratamento; } \\
\text { - } \quad \text { Única ação de saúde registrada foi a desverminação em massa; } \\
\text { - } \quad \text { Não recebem estímulo para prevenção de doenças; tem acesso há exames HIV } \\
\text { - } \quad \text { Nãonas quando solicitado; } \\
\text { - } \quad \text { Agressões físicas graves, sem atendimento (bala alojada e fratura). }\end{array}$ & $\mathrm{X}$ & $\mathrm{X}$ & & $\mathrm{X}$ & \\
\hline $\begin{array}{l}\text { e) Condições de atendimento } \\
\text { - Número de profissionais na área de saúde é insuficiente para atender toda a } \\
\text { demanda dos internos e sem qualquer regime de plantão em caso de necessidades } \\
\text { inesperadas }\end{array}$ & & & & & X \\
\hline $\begin{array}{l}\text { f) Formas de violências } \\
\text { - Internos relataram que já sofreram coação, humilhação, discriminação racial, } \\
\text { agressão física e intimidação por parte da equipe dirigente das instituições } \\
\text { (agressões com uso de um pedaço de madeira). }\end{array}$ & & $\mathrm{x}$ & & & X \\
\hline
\end{tabular}

Fonte: Conselho Federal de Psicologia \& Ordem dos Advogados do Brasil (2006). Elaborado pelos autores. 
Também foram verificados problemas relacionados à falta de higiene pessoal dos adolescentes em instituições das cinco regiões. Dentre as questões apontadas destacam-se os relatos de que a troca de vestimentas ocorre com intervalo de dias; casos em que os adolescentes têm direito a somente uma peça de roupa íntima; bem como, situações em que os adolescentes dormem sobre colchões sujos sem roupa de cama (Quadro 1).

Esses fatores somados (a) às precárias e insalubres condições da infraestrutura física acima mencionadas; (b) aos relatos e queixas, relativamente comuns, acerca da baixa qualidade da alimentação fornecida aos adolescentes; e, (c) ao fato de que nem sempre essas instituições contam com os recursos para realizar a manutenção e a limpeza das instalações habitadas, a exemplo do que foi verificado em algumas instituições da região Nordeste, onde os próprios adolescentes eram incumbidos de realizar a limpeza e higienização das instalações (Quadro 1), evidenciam que esses adolescentes, na ampla maioria das vezes, não são privados apenas da sua liberdade, mas também das condições materiais mínimas para uma vida saudável e digna.

Durante as inspeções também foi denunciada a ocorrência de violência psicológica e física praticada contra adolescentes em unidades de internamento em, pelo menos, duas regiões brasileiras. Foram relatados casos de discriminação racial, coação, constrangimento, humilhação e de agressões físicas (Quadro 1).

Não é de se estranhar que muitos desses adolescentes adoeçam física e mentalmente, durante o período de internação. De acordo com relatório final da inspeção, os problemas de saúde mais comuns entre a população interna, variam desde alergias, problemas odontológicos e doenças infectocontagiosas (escabiose, dermatoses, furunculose, doenças respiratórias, ausência de controle de doenças como tuberculose, DST/HIV/Aids e catapora), até o adoecimento mental que incluem casos de transtornos de humor e transtornos relacionados ao uso de substâncias psicoativas (Quadro 1).

A referida pesquisa também constatou que, muitas vezes, não era assegurada a atenção e a assistência à saúde desses adolescentes tanto em casos de ferimentos, traumas e lesões graves decorrentes de agressões, quanto nas situações mais simples e corriqueiras do dia a dia, como dores de cabeça, febre e desconforto digestivo. Houve relatos da falta de medicamentos básicos e de profissionais de saúde, sobretudo, de dentistas, psicólogos e ginecologistas. Do mesmo modo, as inspeções revelaram a falta de medidas e ações preventivas, tais como a distribuição de preservativos, realização de exames e ações educativas (Quadro 1).

Em 2010, o Conselho Federal de Psicologia divulgou um novo documento, no qual reitera o diagnóstico supracitado, trazendo a público não apenas a falta de novos investimentos em infraestrutura e de recursos para manutenção das instalações e para o custeio de despesas correntes das unidades, como também violações de direitos que decorrem dos próprios limites pessoais e do processo de subjetivação social e profissional daqueles trabalham nas instituições e/ou na rede de serviços de assistência e proteção aos adolescentes internados, conforme destacado abaixo.

Prevalecem em muitas das unidades brasileiras de internação, as condições físicas de superlotação, insalubridade, concepções arquitetônicas inadequadas à proposta do Estatuto da Criança e do Adolescente; ausência de proposta metodológica - propostas claras de funcionamento operacional e rotinas. A isso são somadas circunstâncias mais graves, como tortura física e psicológica, abusos sexuais, maus-tratos, práticas de isolamento e incomunicabilidade, incluindo as mais diversas manifestações de violência - humilhação, medicalização excessiva como mecanismo de docilização dos corpos adolescentes. Atos violentos são praticados pelos adolescentes contra seus pares, contra os adultos, integrantes das equipes das unidades e, de forma preocupante, pelos adultos, integrantes das equipes das unidades, contra os adolescentes (CFP, 2010, p. 21).

Constantino (2019) corrobora com esse entendimento, ressaltando que a efetivação do direito integral à saúde dos adolescentes que cumprem medida socioeducativa em regime de internação é bastante complexa em face das variadas situações de vulnerabilidade e de adoecimento vivenciadas pelos mesmos nesses ambientes institucionais. Ainda, sobre essa questão, Minayo e Souza (2003) já apontavam que os adolescentes internos nesses espaços, com frequência tinham carências nutricionais, doenças sexualmente transmissíveis, problemas de saúde bucal, doenças de pele, dependência de substâncias 
químicas e outras doenças de ordem mental. Além disso, Constantino (2019) acrescenta que as dificuldades para assegurar a atenção integral à saúde desses adolescentes, não raramente, são potencializadas pela frágil articulação entre os serviços da rede de proteção que operam dentro e fora das instituições.

Além disso, um estudo de revisão sistemática integrativa, realizado por Arêas, Constantino e Assis (2017), revelou que um dos temas mais investigados entre a população de adolescentes em conflitos com a lei é a questão da saúde mental, o que tem levado, muitas vezes, a um processo de psicopatologização dos adolescentes e do ato infracional, contribuindo para o predomínio da terapêutica de abordagem biomédica com o uso da medicalização, como forma de controle social e, nas palavras de Michel Foucault (2014), para a docilização dos corpos adolescentes. Ademais, Arêas, Constantino e Assis (2017) destacam que,

A maioria dos estudos analisados aponta a prevalência da lógica menorista nas unidades socioeducativas brasileiras. A prevalência desse modelo de tratamento compromete a saúde, a qualidade de vida e o processo de construção de cidadania dos adolescentes inseridos no sistema socioeducativo, além de potencializar a reincidência e a gravidade dos atos infracionais cometidos (Arêas, Constantino \& Assis, 2017, p. 534).

Cabe destacar que este modo de tratar o adolescente em conflito com a lei, nem de longe, consegue atender as suas necessidades psicossociais e humanas, sobretudo, se for levado em conta que os mesmos se encontram em processo de desenvolvimento e formação.

Para Oliveira (2020), tanto a reformulação da PNAISARI, em 2014, quanto o fortalecimento das políticas intersetoriais ocorrido nos últimos anos da gestão nacional do Partido dos Trabalhadores, de algum modo, possibilitou que questões fossem repensadas e redefinidas, dentre elas, as responsabilidades e competências de cada ente federativo no sistema socioeducativo, inclusive no âmbito da assistência à saúde. Para a autora, esse processo possibilitaria a diminuição dos preconceitos, das iniquidades em saúde entre a população de adolescentes que cumprem as medidas socioeducativas, haja visto que a nova versão da PNAISARI estende o direito à atenção integral à saúde também aos adolescentes do regime aberto.

Contudo, segundo Oliveira (2020) com o golpe parlamentar-midiático-judicial que culminou com o impeachment da presidenta Dilma Rousseff, em 2016, o novo governo, presidido por Michel Temer, acelerou as reformas neoliberais e adotou uma política de austeridade fiscal, legitimada pela Emenda Constitucional n ${ }^{\circ} 95$ de 15 de dezembro de 2016, que restringiu os orçamentos da saúde, da previdência social e da assistência social, impondo severos limites à capacidade dos entes federados de atenderem às diretrizes da referente política.

Ao discutir os desafios enfrentados no sistema socioeducativo do Rio de Janeiro durante a pandemia do Covid-19, Daiane Oliveira (2020) descreve um cenário que, possivelmente, é o mesmo encontrado na ampla maioria dos municípios brasileiros, se caracteriza pelo déficit de profissionais de saúde, pela baixa cobertura de testagem para COVID-19, pela insuficiência de leitos hospitalares, bem como, pela flexibilização das medidas de proteção individual, por parte dos profissionais das unidades socioeducativas. As maiores dificuldades para garantir a atenção integral à saúde dos adolescentes em conflito com a lei nos municípios estudados, decorrem da "redução de investimentos em políticas públicas voltadas ao enfrentamento dos determinantes sociais do processo saúde e doença, do subfinanciamento do SUS e da crise na saúde pública que acomete toda a população" (Oliveira, 2020, p. 6).

Portanto, pensar a implementação de ações que garantam a atenção integral à saúde dos adolescentes preconizada pela PNAISARI, é uma tarefa complexa e desafiadora, visto que, as diversas vulnerabilidades vivenciadas, antes e durante a institucionalização, somam-se aos vazios assistenciais da rede de saúde (Constantino, 2019).

\section{Considerações Finais}

Ao finalizar este trabalho, observou-se que, quando o adolescente em conflito com a lei cumpre medida 
socioeducativa de internação, ele não é apenas privado de suas relações afetivas, familiares e solidariamente próximas, mas também está sendo exposto a uma nova rotina caracterizada pela supressão de sua individualidade, experiência esta que pode ser ainda mais complexa devido a sua condição peculiar de desenvolvimento. Mais do que isso, estará em um ambiente intramuros, sendo submetido às normas, regras e rotinas que forem mais convenientes para a instituição que o acolheu e que, na ampla maioria das vezes, são definidas com base em sua capacidade estrutural e nos recursos materiais disponíveis, sendo fortemente influenciadas pela subjetividade dos seus profissionais e gestores, bem como, das autoridades competentes. Assim, a institucionalização, por si só, pode potencializar o agravamento das condições de saúde, além do mais, podem existir unidades socioeducativas que dificultam o acesso aos serviços ou aos profissionais de saúde, o que torna este grupo duplamente vulnerável.

Isto posto, a aplicação da medida de internação deve ocorrer somente em situações extremas, nas quais existem riscos iminentes à vida do adolescente e/ou de outras pessoas, conforme preconizado pelo ECA, uma vez que, além das possíveis consequências negativas que a privação de liberdade pode ter sobre o desenvolvimento e a vida dos adolescentes, o próprio Estado parece enfrentar dificuldades para garantir as condições objetivas de realização dessa medida socioeducativa, seja pelos próprios desafios, subjetividades e complexidades que envolvem o trabalho socioeducativo, seja pelos interesses e prioridades políticas.

As recorrentes evidências de violações de direitos dos adolescentes privados de liberdade e de seus efeitos deletérios sobre a sua saúde física e mental levaram representantes do Estado e da sociedade civil a lutarem pela implementação de uma política de saúde voltada à esta população, o que resultou na criação da Pnaisari, em 2004.

Contudo, as discussões e considerações realizadas ao longo deste texto apontam que, passadas quase duas décadas desde a criação da referida política, as dificuldades para garantir o direito à atenção integral à saúde dos adolescentes em conflito com a lei ainda são recorrentes em, praticamente, em todo o território nacional.

A literatura sobre o tema evidencia que ainda há um grande fosso entre a lei e a realidade vivenciada nas unidades socioeducativas de internação que, a priori, deveriam se constituir em espaços capazes de proporcionar o acolhimento, a ressignificação das experiências negativas, a restauração e reeducação para vida em sociedade, mas que, na verdade, reiteram o ambiente hostil e desprotegido já conhecido por esses adolescentes na comunidade onde viviam.

Entende-se que a legislação existente é necessária, mas não suficiente para garantir, por si só, a efetivação dos direitos. A despeito da distância entre o ideal da lei e a realidade complexa, acredita-se que tal cenário poderia, em alguma medida, ser superado se, de fato, a legislação fosse cumprida. Como exemplo desse distanciamento, pode-se mencionar algumas ações estabelecidas em lei, que ainda são muito pouco desenvolvidas, tais como: educação permanente para os profissionais das unidades de internação; um sistema de informação de saúde vinculando os internos à assistência do SUS; desenvolvimento de ações e indicadores de saúde da população de adolescentes em regime de internação e internação provisória; reforma e aquisição de equipamentos para as unidades de internação e de internação provisória. A evidente falta de investimentos em formação humana e em manutenção e melhorias estruturais acabam por dificultar a efetivação das condições mínimas necessárias à saúde física e mental dos internos.

Por fim, essas discussões apresentadas neste texto, mostram que, apesar dos avanços positivados em lei e, até mesmo, do que eles já representam em termos de capacidade de mobilização, resistência e enfrentamento das estruturas do poder hegemônico, que concilia os interesses conservadores mais arcaicos com o liberalismo mais perverso, é imprescindível que as lutas continuem para concretizar a saúde como um direito de todos. Para tanto, se faz necessário um comprometimento político e ético dos mais diversos atores sociais, seja como agentes públicos ou como membros da sociedade civil. Evidentemente, há muitas batalhas para lutar e muito trabalho de formação humana a ser feito, para que os direitos sociais e humanos possam ser, de fato, efetivados, assegurando dignidade humana a todos, independente, de raça, de gênero, das condições e experiências 
pessoais e/ou da posição social ocupada pelo indivíduo na sociedade.

Para finalizar estas considerações finais, sugere-se alguns temas para o desenvolvimento de futuras pesquisas: (a) Realizar trabalhos empíricos que permitam a produção de novos conhecimentos para subsidiar o trabalho socioeducativo e a proposição de políticas públicas voltadas às especificidades locais/regionais; (b) Realizar pesquisas para conhecer a efetivação do direito à saúde dos adolescentes que cumprem outras modalidades de medidas socioeducativas, sob a perspectiva dos operadores da política pública, das famílias e dos adolescentes. Para além disso, considerando que a subjetividade humana interfere diretamente na realização e nos alcances de qualquer política pública dirigidas a grupos sociais vulneráveis, entendese ser imperativo o desenvolvimento de formação continuada dos profissionais operadores da política pública e da sociedade civil. No âmbito universitário, a pesquisa e a extensão envolvendo estudantes de diferentes áreas de formação têm um papel fundamental no reconhecimento da realidade social concreta, seja para a aplicação do conhecimento científico, seja como possibilidade de construção de novas subjetividades entre os futuros profissionais.

\section{Agradecimentos}

À Fundação Araucária de Apoio ao Desenvolvimento Científico e Tecnológico do Paraná pela bolsa de iniciação científica concedida a Murilo S. Alves entre 2018 e 2020, sob orientação de Marcos A. M. Arcoverde.

\section{Referências}

Alves, M. S., Rissato, D., \& Arcoverde, M. A. M. (2020). Direito à saúde dos adolescentes em conflito com a lei em privação de liberdade. Trabalho completo apresentado no II Congresso Internacional de Humanidades nas Fronteiras: controvérsias contemporâneas. https://drive.google.com/open?id=1YqaetFxykk27PmDGiKGdY-WUMWO08T51.

Arêas, N. T., Constantino, P., \& Assis, S. G. (2017). Análise bibliográfica da produção em saúde sobre adolescentes cumprindo medidas socioeducativas de privação de liberdade. Physis: Revista de Saúde Coletiva. 27(3), 511-40. https://doi.org/10.1590/S0103-73312017000300008

Bandeira, M. A. (2006) Atos infracionais e medidas socioeducativas: uma leitura dogmática, crítica e constitucional. Editus.

Boas, C. C. V., Cunha, C. F., \& Carvalho. R. (2010) Por uma política efetiva de atenção integral à saúde do adolescente em conflito com a lei privado de liberdade. Revista Médica de Minas Gerais. 20(2). 225-33. https://www.medicina.ufmg.br/wp-content/uploads/sites/37/2011/02/artigo-revista-medica.pdf

Brasil (1988). Constituição da República Federativa do Brasil de 1988. http://www.planalto.gov.br/ccivil_03/constituicao/constituicao.htm.

Brasil. (1990). Estatuto da criança e do adolescente: Lei federal nº 8069, de 13 de julho de 1990. http://www.planalto.gov.br/ccivil_03/leis/18069.htm.

Brasil (1990). Lei n. 8.080 de 19 de setembro de 1990. Dispõe sobre as condições para a promoção, proteção e recuperação da saúde, a organização e o funcionamento dos serviços correspondentes e dá ouras providências. http://www.planalto.gov.br/ccivil_03/leis/18080.htm

Brasil (1997). Portaria n. 1.886 de 18 de dezembro de 1997. Aprova as normas e diretrizes do Programa de Agentes comunitários de Saúde e do Programa de Saúde da Família. Ministério da Saúde.

Brasil (2004). Política Nacional de Atenção Integral à Saúde de Adolescentes em Conflito com a Lei, em Regime de Internação e Internação Provisória (PNAISARI). Portaria Interministerial no 1.426 de 14 de julho de 2004. http://bvsms.saude.gov.br/bvs/saudelegis/gm/2004/pri1426_14_07_2004_rep.htm.

Brasil (2006). Secretaria Especial dos Direitos Humanos. Conselho Nacional dos Direitos da Criança e do Adolescente. Sistema Nacional de Atendimento Socioeducativo-SINASE. Brasília, DF: CONANDA. http://www.conselhodacrianca.al.gov.br/sala-de-imprensa/publicacoes/sinase.pdf

Brasil (2012). Sistema Nacional de Atendimento Socioeducativo (Sinase). Lei nº 12.594, de 18 de janeiro de 2012. www.planalto.gov.br/ccivil_03/_ato20112014/2012/lei/112594.htm.

Brasil (2014). Política Nacional de Atenção Integral à Saúde de Adolescentes em Conflito com a Lei, em Regime de Internação e Internação Provisória (PNAISARI). Portaria GM/MS n ${ }^{\circ} 1.082$ de 23 de maio de 2014. http://bvsms.saude.gov.br/bvs/saudelegis/gm/2014/prt1082_23_05_2014.html.

Calderoni, V. (2010). Adolescentes em conflito com a lei: Considerações críticas sobre a medida de internação. Revista Liberdades. 1(5), 19-53.

Conselho Federal de Psicologia, \& Ordem dos Advogados do Brasil (2006). Um retrato das unidades de internação de adolescentes em conflito com a lei: Inspeção Nacional às unidades de internação de adolescentes em conflito com a lei. $\mathrm{CFP} / \mathrm{OAB}$. https://site.cfp.org.br/wpcontent/uploads/2006/08/relatoriocaravanas.pdf.

Conselho Federal de Psicologia - CFP. (2010). Referências técnicas para atuação de psicólogos no âmbito das medidas socioeducativas em unidades de internação. https://www.crpsc.org.br/ckfinder/userfiles/files/10_\%20Doc_Ref_MSE_UI.pdf. 
Research, Society and Development, v. 10, n. 11, e529101120030, 2021

(CC BY 4.0) | ISSN 2525-3409 | DOI: http://dx.doi.org/10.33448/rsd-v10i11.20030

Constantino, P. (2019). Adolescentes em conflito com a lei: violadores ou violados? Ciência \& Saúde Coletiva. 24(8), 2780-82. https://doi.org/10.1590/141381232018248.17482019 .

Foucault, M. (2014). Vigiar e punir. (42a ed.), Vozes, 2014.

Goffman, E. (2003). Manicômios, prisões e conventos. (7a ed.), Editora Perspectiva.

Köche, J. C. (2011). Fundamentos de metodologia científica: teoria da ciência e iniciação à pesquisa. Vozes. http://www.adm.ufrpe.br/sites/ww4.deinfo.ufrpe.br/files/Fundamentos_de_Metodologia_Cienti\%CC\%81fica.pdf

Lima, D.V.M. (2011). Desenhos de pesquisa: uma contribuição para autores. http://www.objnursing.uff.br/index.php/nursing/article/viewFile/3648/pdf.

Minayo, M. C. S., \& Souza, E. R. (2003). Violência sob o Olhar da Saúde. Editora Fiocruz.

Oliveira, D. (2020). Coronavírus e Sistema Socioeducativo no Estado do Rio de Janeiro: Como fica a saúde dos adolescentes privados de liberdade? Physis: Revista de Saúde Coletiva. 30(3), e300311. https://doi.org/10.1590/S0103-73312020300311.

Perminio, H. B., Silva. J. R. M., Serra, A. L. L., Oliveira, B. G., Morais, C. M. A., Silva, J. P. A. B. ... Franco Neto, T. L. (2018). Política Nacional de Atenção Integral a Saúde de Adolescentes Privados de Liberdade: uma análise de sua implementação. Ciência \& Saúde Coletiva, 23(9), 2859-68. https://doi.org/10.1590/1413-81232018239.13162018.

Tanger, J, P. (2011). Privação de liberdade: a participação dos jovens infratores na construção e avaliação das ações socioeducativas. (Monografia de Especialização, Faculdade de Educação, Universidade Federal do Rio Grande do Sul). https://www.lume.ufrgs.br/handle/10183/72605 